\title{
INTRODUCING GAMIFICATION METHODS TO HIGH SCHOOL STUDENT AT BINA NUSANTARA UNIVERSITY ALAM SUTERA
}

\author{
Arsa Widitiarsa Utoyo \\ School of Design, Visual Communication Design, \\ Universitas Bina Nusantara \\ Jakarta, Indonesia \\ Arsa_w@binus.ac.id
}

\begin{abstract}
Exploration studies in this article highlighted approaches that wearable to increase the value of gamification method to examine the impact of the role of facilitator in the idea of the group. Through the activities, the children of high school/high school were invited as respondents. This activity aimed to stimulate creativity to produce a different settlement with the same results. The presentation material and workshops that used materials of paper and stationeries. Finally, this article outlines recommendations for teaching, learning, and apply gamification in decision making. This method is one of the modern methods of teaching and learning. It starts with forming groups, job descriptions, and the active participation of the students and by comparing the characteristics of the method by way students learn gamification, the positive effects of this method on the educational attainment of students confirmed. Based on the finding of the study the researcher recommended encouraging faculty members to use gamification strategy in teaching, conducting more studies discussing this strategy and its relation to other variables such as critical thinking, conducting more studies on other samples from different study and age levels and from different environments.
\end{abstract}

Keywords: gamification method, student, creativity, university students

\section{INTRODUCTION}

Education is the only way to achieve human ideals desired. Over the past few decades, most of the countries in the world have concerned about the education system that is not quite ready to develop human with required skills and knowledge for a more successful life. In order to deal with fast modern-day and technological developments, it requires the students to improve their ability to think critically and creatively to make the right decisions and be quick in solving complicated problems every day. The most important thing that can pave the way for the emergence of creative ideas and learning is a stable education system [1]. Teaching is reciprocal behavior between educators and students. It is introduced systematically based on the plan by educators in order to create the desired change in the behavior of students [12]. Gamification method was first introduced in 1938 when Alex F. Osborn was seeking ideas [8]. Gamification methods have a rule that serves as a guide for knowledge and not limited to any way in which an educator should clearly spell out these rules to students. After studying the regulations then learners will not have an obsession or self-censorship [1]. The regulations that are used are as follows: (1) It is forbidden to withstand criticism: when they express their ideas, there is nothing to criticize ideas submitted by others, even if it does not make sense. At the end of the session of opinion about different ideas are surveyed. (2) Fly in a dream: this means that during the session, members must put aside all thoughts restrictions. In fact, to think creatively, one must violate common sense and the red line. (3) Focus on quantity: The greater the number of ideas, the easier their classification. (4) Documentation: Every idea, however superficially, to be recorded and the exposing it to other to see it. (5) Combine and improve ideas: Before ideas are evaluated, they must be resolved. Through this, the ideas sloppily presented now revised and completed. The data that will be used in this research is consisted of all female and male student from the "Iconantion" event that held in Bina Nusantara University Campus Alam Sutera with totally 64 students. Gamification strategy is one of the most important strategies in stimulating creativity and problems solving in educational, commercial, industrial and political fields. Gamification strategy was introduced by Alex Osborn, an American advertisement company manager in 1938 as some results of his inconvenience of traditional business meetings. Gamification means the use of brain to the active problem solving to develop creative solutions to problems [8]. On the other hand, creative thinking is known as a compound mental activity aiming to direct a strong desire to look for solutions or reaching original solutions that were not known before [9], from this statement to defined it as the multiple thinking that includes the breaking up of old ideas, making new connections, enlarging the limits of knowledge and the onset of wonderful ideas [7]. Creative problem solving is based on the cognitive theory that adopts the concept of the cognitive structure. It is the mental process of creating a solution to a problem. It is a special form of problem solving in which the solution is independently created rather than learned with assistance. Creative problem solving always involves creativity [11]. It can be defined as a frame of styles designed to help and enhance the problem understanding then generate new and different solution and assess those solutions by using the creative skills [6]. Due to the importance of both concepts (gamification and creative thinking) the current study is to explore the relationship between them especially in developing creative problem-solving skills.

Gamification method is expected to become the foundation in preparing the strategic plan as an effort to make 
improvements and development in creativity as a part of problem solving in educational, commercial, industrial and political fields. Based on the observations in Bina Nusantara University Alam Sutera Campus, most of the students learn difficulties in counting integers. In the daily lessons the lecturer explains in words about counting integers, on the board with examples and with questions and homework but their ability to calculate integers remain low. When the lecturer explains the material in front of the class, most of the students are talking and not paying attention. They are playing around, getting sleepy and even having a daydream. They could not accept the material well so that they feel lazy to participate in learning activities. It is not good that when training is given to students, they do not try to answer the question based on their own thinking, but they answer the question based on another students' answer. Therefore, they are very low, at an average value of 65 students. The cause of the lack of knowledge among other students is that the lecturer cannot choose appropriate learning techniques for materials and the lack of instructional media in learning. Lecturer is lack of attention to students and they more concern in achieving a settlement instead of material mastery of the students. Students only get a lecture on material and they are just as hearers only, they have difficulties in expressing themselves since they are not given the opportunity to express their opinion. At particular, these students are students who are active in classroom management. Based on the above background, the researchers will attempt to increase the activity, creativity and sense of fun students to the lesson of mathematics that will improve their learning outcomes. The research will explain how the learning process in a classroom and how the success rate. To conduct the study, researchers will use a technique of gamification learning undertaken by lectures in in a class with a focus on the students. In this learning, lecturer gives a little problem that involves the subject matter able to stimulate students' thinking so that students are able responding to the problem given by the lecturer. Gamification techniques is expected to increase the activity of students in learning and train them in expressing opinions in accordance with the subject matter being studied. The techniques are expected to improve student learning outcomes

\section{THE STUDY PROBLEM AND QUESNTIONS}

Developing the creative thinking skills especially creative solving of problems because of its importance in helping individuals to cope with international changes and the technology revolution and the communication and interaction in the globalization era. Moreover, it helps in developing creative problem-solving skills as well as a balanced individual's personality capable of social interaction and using self-learning. Further, the role of the teacher had evolved and developed to be a facilitator and trainer, this require him to obtain new teaching methods such as gamification and other strategies that can develop creative thinking skills among students. Therefore, the current study seeks to answer the following questions: There a statistically significant effect at the level of significance $(\alpha=0,05)$ for using gamification program in teaching creative thinking skills development course in enhancing creative problem-solving skills. There a statistically significant effect at the level of significance $(\alpha=$ $0,05)$ in developing creative thinking sub skills. The study objective aims to investigate if there are differences in the means of students' scores on problem skills attributed to gamification program and to exploring the extent of acquiring creative problem-solving skills among the student in the event of "Iconation". The importance of this study emerges from the importance of its variables represented in gamification strategy and creative problem skills. The study is seeking to design a practical program that can be used by the lectures to employ gamification strategy to enable students from generating creative solution problems. The limit of this study sample of student that are come in the "Iconation" event that held at Bina Nusantara University campus Alam Sutera romm 1205, discussed gamification and creative problem-solving variable, teaching of creative thinking skills development courses for degree students, the psychometric characteristics represented in the validity and readability of the creative problem solving skills scale. The procedural definitions using gamification strategy is an innovative conference with special nature in order to produce a list of ideas that can be used as clues lead students to development of problem while giving each students the chance to express the ideas and share those ideas with others and encourage new ideas. A mental process where the gifted uses his experiences and available information to respond the requirements of unfamiliar situation through executing whatever that may solve ambiguity and closing time gaps.

\section{METHODS}

This research was conducted at Bina Nusantara University campus Alam Sutera room 1205 at the time of the event activities "Iconation" held on October 18, 2015 along with student from SMU/SMA/SMK, who were invited to conduct a process of creativity by using paper and stationeries. This activity aims to stimulate creativity to produce a different settlement with the results and the same purpose. Stages used in gamification method: (1) Introducing gamification rules; introducing the rules by writing a list of them on the board and directing the process in class. The students should not try to deviate from the main rule that has been described. (2) Declaring a subject or issue; an educator should choose a topic that has no explicit materials in everyday life. Students must have at least a little bit of information about a topic. To start, lectures give the students an introduction but some interesting information on the topic. (3) Ability to express ideas; this can be done in different ways. One way is that a person presents his/her idea and then the next person take turns to do the same. (3) Showing ideas for combinations and improvements; so far, many ideas have been presented. Now ask the group to refine and improve ideas, namely, to remove repetitive, similar, or inappropriate. Lecturers have to be careful not to throw the original, creative ideas simply for being unusual. (4) Evaluating the ideas; Now lecturers have a 
number of secret ideas. Some people mistakenly believe that group gamification is the whole process of problem solving; while in fact, it is just one of the stages of seeking ideologue, itself became one of the last stages of creative problemsolving [8]. The results of this study showed that the experimental group. The rate of the percentage in the level of creativity performance skills and cognitive attainment of the experimental group which used the method of gamification was better than the rate of percentage in performance skills and cognitive attainment of basic skills in the class.

- The study population of the current study is consisted of all female and male student from the "Iconation" event who invited in Bina Nusantara University Campus Alam Sutera with totally 65 students.

- The study sample is consisted of 65 students from SMU/SMA/SMK in Jakarta and Tangerang, distributed in the class an experimental individual student taught through the training program.

The study instruments using gamification program the one training program is based on gamification strategies containing three sessions within 45 minutes' duration for each those sessions. There three units were taught, those are thinking and its development, critical thinking and creative thinking. Program validity has been displayed on three judges from the faculty members at the Bina Nusantara University, who expressed their views about the program in terms of relevance for the purposes of the study. Two judges out of three agreed with rate of $(80 \%)$ on the validity of this program. Torrance test of creative thinking this test is used to measure the level of creative thinking and its subs skills, it is valid for all age categories as it consists of six tests:

- Asking questions: this requires the individual first to ask any number of questions about some pictures

- Guessing Reasons: the respondent is required to guess all consequences related to the situation in picture.

- Guessing results: the respondent is required to guess all consequences related to the situation in the picture.

- Hypothetical situation: the respondent is required to write all his predictions for the consequences of a hypothetical situation through a picture representing this situation.

The Torrance test was designed to measure three skills; those are:

- Fluency: represented in the possible number of responses for the situation within a time unit.

- Flexibility: represented in the different categories of responses in a fixed unit.

- Originality: represented in the number of fixed and unique responses in a certain time unit.

The Torrance test validity is offered the test to three judges from faculty members who expressed their opinions and agreed on effectiveness of the scale in measuring the total score of creative thinking and the sub scores on originality, flexibility and fluency. The researcher used the (Test-Retest
Method) by applying the test on a random sample consisted of 65 students from the event "Iconation".

\section{FINDING OF THE STUDY}

First results related to the first question is there a statically significant effect at the level of significance $(\alpha=$ 0,05 ) for using gamification program in teaching creative thinking skills development course in enhancing creative problem-solving skills among the student compared to the control group?

The answer the study first question, means and standard deviations were calculated for samples scores on the pre-and post-Torrance test according group variable (experimental) that was taught according the program and the control group which didn't receive any training. Table (1) shows the results.

\begin{tabular}{|c|c|c|c|c|c|c|}
\hline & \multicolumn{3}{|c|}{ Control Group } & \multicolumn{3}{c|}{ Experimental Group } \\
\cline { 2 - 7 } & Number & M & SD & Number & M & D \\
\hline $\begin{array}{c}\text { Pre- } \\
\text { test }\end{array}$ & 51 & 37.59 & 3.24 & 47 & 38.15 & 3.94 \\
\hline $\begin{array}{c}\text { Post } \\
\text { test }\end{array}$ & 51 & 41.45 & 3.20 & 47 & 54.66 & 3.70 \\
\hline
\end{tabular}

Table (1) Means and standard deviations for samples scores on the pre-and post-Torrance test per group variable.

Table (1) shows that there are differences between the two means of students' scores on pre-and post-Torrance test in both groups. To investigate the statistical significance between the two administrations per group variable.

\begin{tabular}{|c|c|c|c|c|c|c|}
\hline $\begin{array}{c}\text { Varianc } \\
\mathrm{e}\end{array}$ & Squre & $\mathrm{df}$ & Squre M & $\mathrm{F}$ & sig & $\begin{array}{c}\text { Effec } \\
\text { t Size }\end{array}$ \\
\hline Pre & 300.846 & 1 & 300.846 & 34.011 & .000 & .264 \\
\hline Group & $\begin{array}{c}4065.55 \\
0\end{array}$ & 1 & $\begin{array}{c}4065.55 \\
0\end{array}$ & $\begin{array}{c}459.61 \\
1\end{array}$ & $\begin{array}{c}.000 \\
*\end{array}$ & .829 \\
\hline Error & 840.335 & 9 & 8.846 & & & \\
\hline Total & $\begin{array}{c}5206.73 \\
0\end{array}$ & $\begin{array}{c}9 \\
7\end{array}$ & & & & \\
\hline
\end{tabular}

Table (2) Results of analysis of covariance (ANCOVA) for student scores on the pre-and post-Torrance test according group variable

Table (2) shows that there are statistically significant differences at the level of $(\alpha-0,05)$ between the two means of student scores on posttest in the both groups. F value totaled (459.611) showing a statistically significant value at $(\alpha=$ $0.000)$. to determine the value of performance on pretest.

\begin{tabular}{|c|c|c|}
\hline Group & Modified means & Standard Error \\
\hline Experimental & 41.58 & 0.42 \\
\hline Control & 54.52 & 0.44 \\
\hline
\end{tabular}


Table (3) modified means of students' scores in both groups on Torrance posttest after eliminating the effect of performance on pretest.

Table (3) shows that the differences were in the favor of the experimental group who was taught through the program as the modified means totaled (54.52), it is higher than the modified means of the control group who didn't receive any training as the modified means totaled (41.58). Eta Square was used to find the effect size, it totaled (82.9\%) this means that the group variable explains $(82.9 \%)$ of the variance in means between both groups on the test. Second, results related to the second question: Is there a statistically significant effect at the level of significance $(\alpha=0.05)$ in developing creative thinking sub skills of the experimental group compared with the control group? To answer this question means and standard deviations were calculated for the samples' scores on each skills of creative test according group variable (experimental that was taught according the program and the control group which didn't receive any training). Table (4) shows the results.

\begin{tabular}{|l|l|l|l|l|l|l|l|}
\hline Skill & \multicolumn{5}{|l|}{ Control Group } & \multicolumn{2}{l|}{$\begin{array}{l}\text { Experimental } \\
\text { Group }\end{array}$} \\
\hline & & No & M & SD & No & M & SD \\
\hline Fluency & $\begin{array}{l}\text { Pre- } \\
\text { Test }\end{array}$ & 51 & 24.61 & 2.38 & 47 & 24.49 & 2.42 \\
& $\begin{array}{l}\text { Post } \\
\text { Test }\end{array}$ & 51 & 25.49 & 2.55 & 47 & 32.96 & 1.77 \\
\hline Flexibility & $\begin{array}{l}\text { Pre- } \\
\text { Test }\end{array}$ & 51 & 9.41 & 1.08 & 47 & 10.04 & 1.30 \\
\hline & $\begin{array}{l}\text { Post } \\
\text { Test }\end{array}$ & 51 & 11.22 & 1.51 & 47 & 15.02 & 2.15 \\
\hline Originality & $\begin{array}{l}\text { Pre- } \\
\text { Test }\end{array}$ & 51 & 3.57 & 1.47 & 47 & 3.62 & 1.66 \\
\hline & $\begin{array}{l}\text { Post } \\
\text { Test }\end{array}$ & 51 & 4.75 & 1.53 & 47 & 6.68 & 1.73 \\
\hline
\end{tabular}

Table (4): Means and Standard Deviations for the Samples' scores on Torrance tests according group variable

Table (4) shows that there is an apparent difference the two means of students' scores on each skill for pre-and postcreative test in both groups. To investigate the significance of those differences according group variable: (experimental that was taught according the program and the control group which didn't receive any training) after eliminating the differences on the pretest Two Way ANCOVA test was used at the level of $(\alpha=0.05)$. The tools that will be used to test whether the method of gamification is success or failure are simple equipments of stationary and a sheet of paper. The process is done by providing an image to children of SMU/SMA/SMK who attends the event at the Universitas Bina Nusantara "Iconantion" in Alam Sutera. Some pictures of pineapple fruit are used as a rationale for testing the ability of the children's creativity. Selection of images of pineapple fruit is quite easy to find and has an attractive shape and color. Each student is required to create an attractive image to their liking so that they can channel all their ideas and thoughts without any restrictions and doubts. The explanation about the presentation slide in is as follows: (1) Designing creativity through gamification method. (2) What is gamification. (3) Learning gamification. (4) The different between left and right brain. (5) Sample. The study objective is to investigate if there are any differences in the means of student scores on problem solving attributed to the gamification program and in exploring the extent of acquiring creative problem skills among the students. The study is seeking to design a practical program that can be use by lectures to employ gamification strategy to enable students from generating creative solutions for problem, the study is conducted within the following limits: (1) A sample of high school students at Bina Nusantara University Alam Sutera Campus. (2) The study discussed gamification and creative problem solving variables and findings are limited to those variables within the used procedures. [3] defines gamification as a group creativity forum for general ideas [13]. Gamification is developed by Alex Osborn to produce ideas without inhibition. Gamification technique involves oral and pre-writing exercises for helping the learner and for expressing ideas by the lectures. It is a technique that is used under the discussion method. Gamification has great importance in the teaching process. The great importance for students are as follows: (1) Helping students to solve problems, an innovative solution. (2) Helping students to benefit from the ideas of others through the development and build on them. (3) Helping the cohesion of the students and build relationships among them and assess the views of others. (4) Helping the lectures to conclude ideas that are broader than students' solutions. (5) Making the lectures more democratic and respectful of views regardless of the different points of view. The major purpose of gamification as a teaching strategy is to foster and enhance communication skill, help to promote thinking and decisionmaking skill and foster different viewpoints and opinions. It may equally be used in all key areas of learning. However, the major limitation is that it is generally not suitable for younger levels because of the level of reasoning required for it to work. The lecture must equally be able to guide and give aid as necessary considering the class environment as such considerations often determine the outcomes. In gamification techniques, the instructor carefully plans the lesson to reach the desired learning outcomes. The group interacts in response to questions and the instructor refrains from entering the discussion as an active participant. Students are encouraged to learn about the subject by actively sharing information, experiences, and opinions. The flow of communication is a transaction among all the students rather than recitation and response between individual students and the instructor. Abwli (2006) mentioned stages that must be followed in 
problem solving within the gamification session, those are: (1) Phrasing the Problem: the lecturer who is responsible on the sessions offers a problem and discusses its various dimensions for students to ensure understanding. (2) Framing the problem: in this stage the lectures determines the problem accurately by reframing the problem in certain questions. This may offer acceptable solutions without the need for further gamification. (3) Practicing gamification for one or more than one statement in problem This step is very important as many ideas are generated. [4] Mentioned that this step needs: (1) Conducting warming up session 2 (two). Receiving ideas even if they are nonsense. (2) Offering the four principles of gamification on the board in order to be seen by students. (3) Writing and presenting all ideas (Proposed solutions). (4) Frustration and boredome must be avoided. Gamification session lead to generate a big number of ideas and therefore, those ideas must be evaluated and select the most suitable and important ones according novelty, originality, usefulness, duration and cost as well as logic [6]. Researcher's test is used to measure the achievements made in the education of students. The test consists of a single image already choose generally making it easier for students to analyze. To determine which are attractive and unattractive from the results of the evaluation. The results of the study presented is the result of analysis of quantitative and/or qualitative with an emphasis on the answers to the issues discussed in a comprehensive manner. Results are descriptive terms, images, and others that facilitate understanding for lectures and other students. The material of the unit training program is planned and designed to assist and help the participants in achieving the training objectives. The training package involves the unity of form, content and context. The training model approach of instructional system and the guidance of the trainers make participants feel easier to use a very different model like this beside usual handouts, exercise books and other writing materials. The function of the training method is to increase the motivation of creative gamification, art and critical thinking. The participants could realize a consistent training to learn to be independent and to improve care for other groups and individuals. Creative activities provided in the form of material containing a description of the facts or data exposure, concept, principle, proposition, theory, values, procedures, skills, problems that are presented in a narrative or pictorial. Examples and illustrations in the form of objects, letters and pictures that represent concepts to strengthen participants' description of the material. The number of participants 64 students as many as three faculty instructors from Bina Nusantara University majoring in Visual Communication Design.

\section{RESULTS AND DISCUSSIONS}

The number participants as many as 64 students of any high school in Jakarta and Tangerang that came to the "Iconantion 2005" event in Bina Nusantara University Alam Sutera on the date October 18 '2015. The program has been displayed on three judges from the faculty members at Bina Nusantara University who expressed their views about the program in terms of relevance to the study. Three judges are agreed with a rate of $100 \%$ on the validity of this program. This test is used to measure the level of creative thinking and its sub skills, it is valid for all age categories as its consists of six test: (1) Asking questions: this requires the individual first to ask any number of questions about a picture. (2) Guessing Reasons: the respondent is required to guess all consequences related to the situation in the picture. (3) Guessing Results: the respondent is required to guess all consequences related to the situation in the picture. (4) Enhancing Product: this test requires respondent to think of the smartest and novel ways to make a doll more interesting for children. (5) Unusual usage: Requires respondent to think of the biggest number of uses for empty cartoon boxes. (6) Hypothetical situations: the respondent is required to write all his predictions for the consequences of a hypothetical situation through a picture representing this situation.

Torrance test was designed to measure three skills; those are: (1) Fluency: represented in the possible number of responses for the situation within a time unit. (2) Flexibility: represented in the different categories of responses in a fixed time unit. (3) Originality: represented in the number of fixed and unique responses in a certain time unit.

\begin{tabular}{|l|l|l|l|}
\hline Skill & Group & $\begin{array}{l}\text { Modified } \\
\text { mean }\end{array}$ & $\begin{array}{l}\text { Standard } \\
\text { Error }\end{array}$ \\
\hline Fluency & Control & 25.44 & .20 \\
\hline & Experimental & 33.02 & .21 \\
\hline Flexibility & Control & 11.30 & .26 \\
\hline & Experimental & 14.93 & .27 \\
\hline Originality & Control & 4.65 & .22 \\
\hline & Experimental & 6.78 & .23 \\
\hline
\end{tabular}

Table (5): Modified means of students' scores in both groups on Torrance posttest for each skill after eliminating the effect of performance on pre-test

Table (5) shows the modified means for the students' scores in the experimental group and the control group on each skill of post creative thinking test (originality, flexibility and fluency) after eliminating the differences on the pretest. Differences were in the favor of the experimental group who was taught through the training program as the means were $(6.78,14.93$, 33.02) respectively and it is higher than the means of the control group that totaled $(4.65,11.30,25.44)$. To find the effectiveness of the method Eta square was calculated, it totaled $(31.0 \%, 50.0 \%, 87.4 \%)$. This means that the group variable interprets $(87.46 \% 50.06 \% 31.0 \%)$ respectively on the variance between the means of student's performance on each skill of Torrance creative thinking test. As seen above, there is a statistically significant difference between the means of the performance of the group that received training and the control that didn't receive any training even in the total score of the test or its sub skills. This may be attributed to the nature of gamification strategy as a collective discussion strategy that encourage students to generate the highest number of ideas that are varied and creative in a spontaneous and free open climate that is not critical and doesn't limit the freedom of 
launching ideas. Moreover, its nature based on phases allows students to move from one step to another freely after completing the previous step. The test offered to judges faculty members who express their opinions and agree on the effectiveness of the scale in measuring the total score of the creative thinking and the sub scores on originality, flexibility and fluency. Figure 5 shows the result of the creative and thinking and how they can use visual as the creative problem solving on every problem they get in the real lives; this means the student respectively perform each skill of creative thinking test. As seen on figure 4, there is a significant difference between the performance of students that received the training properly and those that did not receive training properly even in the test or their sub skills. It may be attributed to the nature of gamification strategy as a collective discussion strategy. It encourages student to generate the highest number of ideas that are varied and creative in a spontaneous and free open climate that is not critical and does not limit the freedom of launching ideas. Moreover, its nature base on phases allows students to move from one step to another freely after completing the previous step. The effect on this strategy in developing creative thinking and in its sub, skills may be attributed to the advantages of this strategy that are accepted among students. Some of those advantages are the element prepared and students' read to participate in the sessions as well as joy environment that provide the students with a free climate that does not contain any critics and interference. Based on the findings of the study, is recommended: (1) Encouraging Faculty members to use gamification strategy in teaching. (2) Conducting more studies discussing this strategy and its relation to other variables such as critical thinking. (3) Conducting more studies on other samples from different study and age levels and from different environments.

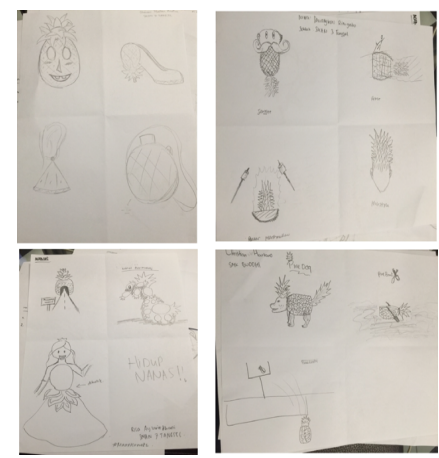

Figure 2 Best Result take using personal camera

The findings of this study are Consistent with the Darayseh, [2][3].

\section{CONCLUSIONS}

Based on the finding of the study the researcher recommended encouraging faculty members to use gamification strategy in teaching, conducting more studies discussing this strategy and its relation to other variables such as critical thinking, conducting more studies on other samples from different study and age levels and from different environments. In general, the effect on the students' gamification teaching methods shows that they can make a wide range of conclusions without restriction so that they can make clear-minded, careful and quick in decision making. This finding is consistent with the results of some research on gamification and other active teaching methods. In other words, it can be concluded that the positive gamification method is effective in student's educational attainment. This method is one of the modern methods of teaching and learning. It starts with forming groups, job descriptions and the active participation of the students and by comparing the characteristics of the method by way students learn gamification. The positive effects of this method on the educational attainment of students confirmed. Suggestions can be delivered based on the research that has been done in this study, namely: recommended to students as well as students to create a learning environment that provides opportunities for group of their students and who are not in the group to be able to issue their answer. In addition, it should also be encouraged to make reflection on the decision-making process that has taken place to get results that correspond to upcoming destinations and has been agreed from the beginning, Other researchers who are interested to conduct further research on the learning model based methods Gamification are suggested to pay attention to the constraints experienced in this study as consideration for the repair and improvement of the research to be carried out. Based on the findings of the study, it is recommended to encourage faculty members to use gamification strategy in teaching, conducting more studies in discussing this strategy and its relation to other variables such as critical thinking and conducting more studies on other samples from different study and age levels and from different environments.

\section{REFERENCES}

[1] Aghazadeh, M. (2005). New Methods of Teaching Guide. Tehran: Yyzh Publication.

[2] Al-bwli, Q. (2006). The effectiveness of using gamification strategy in developing creative thinking in Islamic Education among Third secondary students in Tabouk City (Master Thesis). Mut'a University, Krak. Jordan

[3] Al-maghawry, A. (2012). Effectiveness of Using the Gamification Technique to Learn Some Basic Skills and Collection of Knowledge for Beginners in Volleyball. World Journal of Sport Sciences, 6(4), 361-366

[4] Al-qarni, F. (2011). Measuring the effectiveness of using brainstorming strategy in developing creative thinking in science among third intermediate students in Qurayyat city (Unpublished Master thesis). Al-balqa Applied university, Salt. Jordan.

[5] Bani Hamad, F. (2006). The effect of brainstorming strategy in Graduate studies students (Master Thesis). Amman Arabic University. Jordan.

[6] Gardener, H. (1999). Intelligence Reframed. Multiple intelligence for the 21 century. Retrieved from: http://search,epent.com/login.aspx.

[7] Honig, A. (2001). How to Promote Creative Thinking. Early Childhood Today, 15(5), 34-41. 
[8] Hryrfrosh, G., Sadeghi, M. (2010). Teaching Pattern of Brainstorming.

[9] Jarwan, F. (2005). Teaching Thinking: Definition and applications. Amman: Dar Al-fkir, Jordan.

[10] Jarwan, F. (2008). Giftedness and Talents. Amman: Dar Alfkir, Jordan.

[11] Qattami, N. (2010). Methods of teaching gifted and talented. Amman: Dar Al-maseera.

[12] Shabani, H. (2001). Skills Education. Tehran: SAMT.

[13] Zeitoun, A. (2001). Methods of Teaching Science, Amman: sunrise house for Obada, A. (1992). Creative Solutions of Problems: Theory and Practice 